\title{
Information Technology Acceptance in Health Information Management
}

\author{
M. Abdekhoda; M. Ahmadi; A. Dehnad; A. F. Hosseini \\ School of Health Management and Information Sciences, Iran University of Medical Sciences, Tehran, Iran
}

Keywords

Information technology, health information management, technology acceptance model, user acceptance, user perceptions

\section{Summary}

Objective: User acceptance of information technology has been a significant area of research for more than two decades in the field of information technology. This study assessed the acceptance of information technology in the context of Health Information Management (HIM) by utilizing Technology Acceptance Model (TAM) which was modified and applied to assess user acceptance of health information technology as well as viability of TAM as a research construct in the context of HIM.

Methods: This was a descriptive- analytical study in which a sample of 187 personnel from a population of 363 personnel, working in medical records departments of hospitals affiliated to Tehran University of Medical Sciences, was selected. Users' perception of applying information technology was studied by a researcher-developed questionnaire. Collected data were analyzed by SPSS software (version16) using descriptive statistics and regression analysis.

Results: The results suggest that TAM is a useful construct to assess user acceptance of information technology in the context of HIM. The findings also evidenced the perceived ease of use (PEOU) and perceived usefulness (PE) were positively associated with favorable users' attitudes towards HIM. PU was relatively more associated $(r=0.22, p=0.05)$ than PEOU $(r=$ $0.014, \mathrm{p}=0.05$ ) with favorable user attitudes towards HIM.

Conclusions: Users' perception of usefulness and ease of use are important determinants providing the incentive for users to accept information technologies when the application of a successful HIM system is attempted. The findings of the present study suggest that user acceptance is a key element and should subsequently be the major concern of health organizations and health policy makers.

\section{Introduction}


Information Technology (IT) is defined as "the group of technologies that is revolutionizing the handling of information and embody a convergence of interest between electronics, computing and communication" [1]. Since the early 21 st century, IT has undergone rapid advances affecting information systems and their respective areas considerably, and health information management is no exception. The use of IT in healthcare systems has promoted healthcare quality and the access to healthcare services leading to a noticeable reduction in medical errors and costs [2]. However, thoughtful attention to IT acceptance is required, when implementing any HIT system. Internet-based health applications including electronic health records, electronic prescribing, and mobile health, according to the Medical Records Institute (2003), are the ultimate goals of most healthcare organizations [3]. The discussion on the use of the Internet, for enhancing the efficiency of healthcare industry and reducing errors in care delivery processes, has been tackled in many studies [4]. Regardless of these potentials, implementation of health information systems are lagging behind its adoption in health care organizations [5].

The literature shows that there are many barriers to the implementation of IT in healthcare organizations [6, 7]. The barriers are mainly observed in the areas where human issues, economics and technologies are involved. Among these barriers, human issue is by far more fundamental than the other barriers and its ignorance makes the resolving of the other two issues unlikely. User acceptance of technology, categorized under human issue, is the first key element in applying IT in healthcare services [8] and has been an important area of interest initiated in the 1970s, when there was an increasing demand in technology for research due to failures of system adoption in health organizations. Recently, a number of other barriers responsible for hindering the development and implementation of IT in healthcare have been identified. A change in physicians' efficiency, low familiarity with technology, inadequate legal framework, lack of explicit standards, interoperability problems of application systems, confidentiality and privacy concerns, time shortage, and insufficient research are some of the variables related to the aforementioned barriers $[9,10]$.

Human issues including resistance to change, user acceptance, persistence and failures highlight the emerging focus on user acceptance in a number of health organizations [11]. Although the universal perception of IT integration suggests that it is of vital importance to physicians and healthcare providers, the literature provides evidence of the failure of health system implementations, due to the ignorance of user acceptance [11].

\section{Theory and Hypotheses}

There are a wide variety of theoretical perspectives developed to understand users' mental processes when an organization decides to adopt IT systems. However, most of the studies conducted in this area have failed to provide reliable measures that could explain and evaluate system acceptance or rejection [12]. User acceptance of technology, categorized under human issue barriers, is the first key element in applying IT in health care services $[8,13]$ and has been an important area of interest for many researchers. This interest was initiated in the 1970s, when there was an increasing demand in technology, and stemmed from the failures of system adoptions in organizations. A wide variety of theoretical perspectives have been developed to understand the users' mental processes when deciding to use technology applications. 
The most dominant IT theories providing proper models for understanding the success and failure of IT applications appear to be Innovation Diffusion Theory (IDT) [14], Theory of Planned Behavior (TPB) [15], the Unified Theory of Acceptance and Use of Technology (UTAUT) [16] and the Technology Acceptance Model(TAM) [17]. These theories present proper tools for assessing the success and failure of IT applications [18]. For example, Duych et al. (2008) applied UTAUT to predict and gain best understanding of user acceptance of the picture archiving and communication system (PACS) in a radiology setting.

They found that UTAUT functioned well in predicting end-users' intention to use PACS [19]. Technology Acceptance Model (TAM), developed by Davis et al. in 1989 [17], explains the acceptance of IT in performing tasks and introducing two fundamental ideas influencing the use of information systems: Perceived Usefulness (PU) and Perceived Ease of Use (PEOU). PU is defined as "the degree to which an individual believes that using a particular system will enhance his or her job performance". PU is related to job effectiveness, productivity, time saving, and the relatively significant role of the systems in a user's job. On the other hand, PEOU is defined as "the degree to which an individual believes that using a particular system is free of effort" i.e., physical and mental efforts as well as ease of learning. PU and PEOU may be influenced by various external variables including user characteristics such as level of education and gender and organizational features such as on the job training. These variables have been found to influence users' intention to use IT [1].

The literature shows several studies on users' acceptance of technology conducted by the use of TAM. "Specifically, the TAM theorizes that a user's intention to utilize a new information system may be influenced by his or her perceptions as to whether the system will be useful and easy to use" [20]. TAM has extensively been applied to gain a better understanding of IT adoption and use in organizations where students, business managers, clerical and different administrative types are engaged [12].

In a systematic review, conducted by Holden and Karsh (2012), over 20 studies in 16 databases related to clinicians using health IT for patient care, were analyzed. Reviewing the studies using TAM and other related models, the authors concluded that "there is great interest in TAM in healthcare and ample opportunity for its success, but whether TAM evolves into a theory of heath IT, as opposed to theory for heath IT, is still to be seen" [21]. Hulse et al. (2006) noted that TAM was fit to assess and anticipate end-users' favorable attitudes towards using knowledge authoring tool. Also, they showed that PU was directly associated with user intention to apply the knowledge- based systems, while PEOU showed an indirect association [22].

However, the researchers have found no studies evaluating TAM in healthcare and health information management in Iran. The present study aimed at examining TAM to determine the assessment fit for the acceptance of IT in HIM, inparticular in Iran. Moreover, the present study attempted to propose some modifications for accepting IT in HIM in Iran and for further evaluation of Information technology acceptance in other settings. In this study, user acceptance of IT and health information systems were analyzed from the perspective of user perception. The modified model assessed PU, PEOU, and attitude towards using IT the use of which and other relationships between TAM variables are shown below 


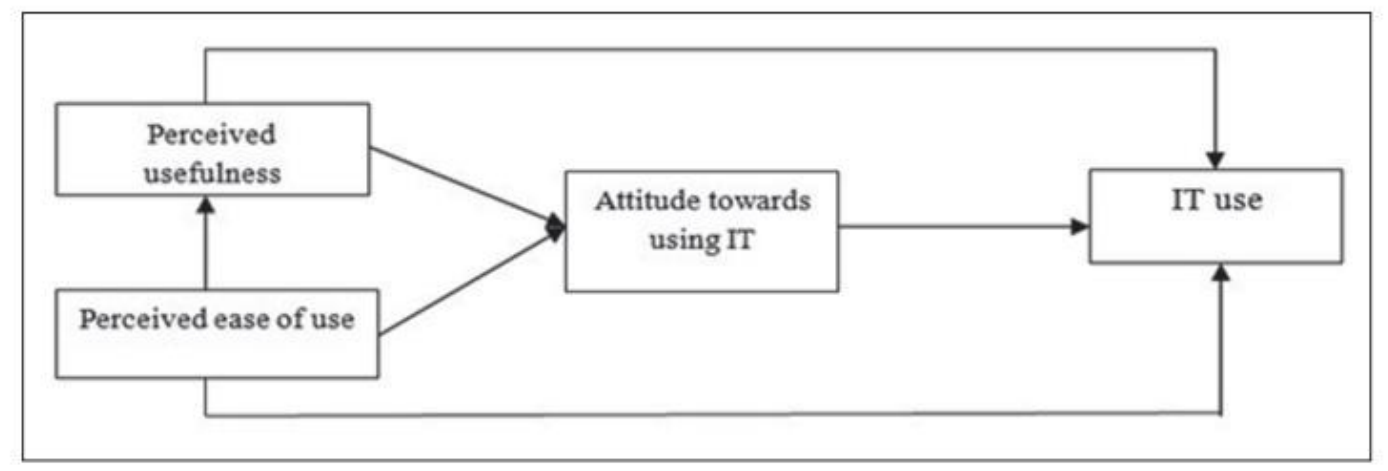

Figure 1

Research model

The literature shows that many of the TAM-based models have reported that attitudes toward using IT is drawn largely from the user's perception of usefulness [23, 24]. It is believed that PU is the antecedent of health professionals' intention for using IT systems. Inspired by previous studies (Ortega Egea, 2011; Wu 2008; Pai, 2010) reporting that the relationship between PU and personnel's attitude towards IT and the use of IT should be taken into consideration for accepting IT by users in health information services, the following hypotheses, $\mathrm{H} 1$ and $\mathrm{H} 2$, were put forth:

- H1. PU is positively associated with personnel's favorable attitudes towards IT.

- H2. PU is positively associated with personnel's use of IT.

The literature shows inconsistent findings for the relationship between PEOU and attitude towards using IT [24, 25]. Lee (2003), through a systematic review, found that only 58 studies reported a significant relationship between PEOU and dependent variables such as attitude and actual use of IT, suggesting that PEOU is an unstable measure in predicting dependent variables [26]. Subramanian (1994) and Igbaria et al. (1995) found no significant relationship between PEOU and attitude [27, 28] while a number of studies maintained that PEOU could indirectly affect the acceptance of IT through PU [29] and PEOU which might be a determining factor in accepting IT. Thus, the following hypotheses, H3, H4 and H5, were followed by this study:

- H3. PEOU is positively associated with personnel's favorable attitude towards IT.

- H4. PEOU is positively associated with personnel's use of IT.

- H5. PEOU is positively associated with PU.

Attitude towards the use of IT, as the second most important predictor of physicians' intention to use telemedicine services, were addressed by Chau and $\mathrm{Hu}$ (2002)[30]. Davis et al. (1989) found that there was a direct relationship between attitude and the use of IT implying that people will intend to use an IT system when they evaluate it positively (12). Hence, hypothesis 6 (H6) was presented as follows: H6. Attitude towards the use of IT is associated with IT usage.

\section{Materials and Methods}


The research methodology included the following steps: selection of research setting and population, selection and modification of survey instrument, pre-testing the survey instrument with a pilot population and modifying it by applying necessary changes, distributing the questionnaire, and finally analyzing the results. Currently, in Iran, the adoption of IT and electronic health services such as Electronic Medical Record (EMR) and online prescriptions are encouraged and rewarded by government, especially in healthcare centers of medical science universities. It is anticipated that IT will eventually be implemented and used in all medical facilities by the personnel of medical records departments working with Registration, Admission, and Discharge and Transfer (RADT) systems in hospitals. The population of this study included 363 personnel in medical records departments of Tehran University of Medical Sciences. There were two reasons for selecting TUMS as the setting of the study: it was the largest and the first rank medical university in Iran and there had been a high intention for the adoption of new technologies especially health information technologies in TUMS. Hospital Information System (HIS) is the technology generally applied by medical records personnel of TUMS.

A sample of 187 participants from the population of 363 persons working in medical records departments of Tehran University of Medical Sciences was selected by stratified random sampling. A pilot study was performed before conducting the final version of the instrument in order to prevent the problems emerging when the instrument of the study would be used.

A researcher-made questionnaire on the basis of Wilkins' (2008) and Nair's (2011) questionnaires was developed for data collection [31, 32]. Wilkins evaluated heath information mangers' perceived usefulness and perceived ease of use of an electronic heath care record system. Nair used tech-nology acceptance variables such as PU and PEOU to serve as a future initiative guide for healthcare departments which did not adopt electronic health records by the time of the study. The content and face validity of the questionnaire were confirmed by five faculty members of health information management department in TUMS. The reliability of the questionnaire was measured by test-retest (91.2). The survey consisted of 28 structured questions on PU of IT for work efficiency and effectiveness; PEOU of IT, attitude towards IT, and use of IT in routine works. The questions were designed in a way that could help identify factors personnel of medical records departments of Tehran University of Medical Sciences perceive as impotent in decisions they make to adopt IT. There were also a number of demographic questions. "To -tally agree", "Agree", Neutral", "Disagree", and "Totally disagree", formed the questionnaire which was based on 5-point Likert scale. In this study, perceived usefulness and perceived ease of use were independent variables, while attitude toward IT and actual use of IT were dependent variables.

Table 1 shows the questions used in the survey measuring the various constructs in TAM when Technology Acceptance Model is to be used. The survey was administered by using TUMS webmail services. An introductory e-mail explaining the purpose of the surveys as well as key terminology were sent for the participants of the study. A correlation matrix was constructed to identify the relationship between variables and to simplify the model prior to testing. A graphical path model was developed to replicate the proposed research model( $\bullet$ Figure 1). Anonymous questionnaires were used and consent form was made for participation of this study. From 187 questionnaires, 132 of them were completed and returned, but at the end, 120 questionnaires

Abdekhoda M, Ahmadi M, Dehnad A, Hosseini AF. Information technology acceptance in health information management. Methods of information in medicine. 2014 Jan 1;53(1):14-20. 
were appropriate for analysis. The collected data were analyzed by SPSS software (version 16). The relationship between variables was assessed by a regression test. Pearson's correlation was applied to examine the relationship between variables.

Descriptive statistics were used for reporting the level of acceptance of IT among the personnel. Finally, the modified model was tested and presented.

Table 1 Items used to measure the various constructs in TAM model

\begin{tabular}{|c|c|c|}
\hline Construct & $\begin{array}{l}\text { Item } \\
\text { Number }\end{array}$ & Items \\
\hline \multirow{5}{*}{$\begin{array}{l}\text { Perceived } \\
\text { usefulness }\end{array}$} & 1 & Using IT in my job would enable me to accomplish tasks more quickly. \\
\hline & 2 & Using IT improve my job performance. \\
\hline & 3 & Using IT would make it easier to do my job. \\
\hline & 4 & Apply IT are useful in my job. \\
\hline & 5 & By using IT, my productivity would be increased. \\
\hline \multirow{4}{*}{$\begin{array}{l}\text { Perceived ease } \\
\text { of use }\end{array}$} & 6 & I believe that interaction with IT would be clear and understandable. \\
\hline & 7 & I believe navigation of IT would be easy. \\
\hline & 8 & Learning to operate IT would be easy for me. \\
\hline & 9 & IT would be easy for me to become skillful at using IT. \\
\hline \multirow{4}{*}{$\begin{array}{l}\text { Attitude toward } \\
\text { IT }\end{array}$} & 10 & I am willing to use IT for my work. \\
\hline & 11 & I do not mind spending some time to learn how to use IT for my work. \\
\hline & 12 & I believe that using IT in my work is necessary. \\
\hline & 13 & Using IT is good idea. \\
\hline \multirow{3}{*}{$\begin{array}{l}\text { Actual usage of } \\
\text { IT }\end{array}$} & 14 & I use IT in my work routinely. \\
\hline & 15 & I would like to use IT in my work in future. \\
\hline & 16 & Many of routinely work was carried out by using IT in my job. \\
\hline
\end{tabular}

\section{Results}

Table 2 shows demographic information of the study sample. As this table shows, the majority of the respondents (76 percent) were female. The mean age of the participants was 31 and more than half of the participants (56.2 percent) were in the age range of $24-30$. About two thirds of the participants (65.3 percent) had bachelor degree and 80.2 percent were medical records graduates. The data showed the mean year of 7.9 for the participants' work experience while less than half of them had 6-10 years of work experience. 
Table 2 Demographic information of the sample

\begin{tabular}{|c|c|c|c|c|c|}
\hline Demographics & & Freq. & Per. & mean & SD \\
\hline \multirow[t]{3}{*}{ Gender } & Male & 28 & 23 & & \\
\hline & Female & 92 & 76 & & \\
\hline & Total & 120 & 100 & & \\
\hline \multirow[t]{5}{*}{ Age } & $24-30$ & 68 & 56.2 & \multirow{5}{*}{31} & \multirow{5}{*}{4.4} \\
\hline & $31-35$ & 34 & 28.1 & & \\
\hline & $36-40$ & 12 & 9.9 & & \\
\hline & $\leq 41$ & 6 & 5 & & \\
\hline & Total & 120 & 100 & & \\
\hline \multirow[t]{5}{*}{ Degree } & Diploma & 3 & 2.5 & & \\
\hline & Associate degree & 29 & 24 & & \\
\hline & Bachelor & 79 & 65.3 & & \\
\hline & Master & 9 & 7.4 & & \\
\hline & Total & 120 & 100 & & \\
\hline \multirow[t]{3}{*}{ Field of study } & Medical records & 97 & 80.2 & & \\
\hline & Other & 23 & 19 & & \\
\hline & Total & 120 & 100 & & \\
\hline \multirow[t]{5}{*}{ Work experience } & $2-5$ & 39 & 32.2 & \multirow{5}{*}{7.9} & \multirow{5}{*}{3.9} \\
\hline & $6-10$ & 56 & 46.3 & & \\
\hline & $11-15$ & 19 & 15.7 & & \\
\hline & $10-20$ & 6 & 5 & & \\
\hline & Total & 120 & 100 & & \\
\hline
\end{tabular}

Table 3 shows the relationship between dependent and independent variables. As it is seen, there is a significant relationship between PU and attitude $(\mathrm{r}=0.22, \mathrm{p}=0.05)$. It was also found that PU was positively associated with personnel's favorable attitudes towards IT $(r=0.22, p=0.05)$. The findings showed PU is positively associated with participants' use ofIT $(r=0.37, p=0.05)$. Table 3 indicates a positive association of PEOU and personnel's favorable attitudes towards IT $(\mathrm{r}=0.14, \mathrm{p}=0.05)$, and shows, PEOU was positively associated with personnel's use of IT $(\mathrm{r}=$ $0.36, \mathrm{p}=0.05)$. 
Table 3 The relationship between dependent and independent variable $\left({ }^{*} p=0.05\right)$

\begin{tabular}{|l|l|l|l|l}
\hline \multicolumn{2}{|c|}{ Dependent variable } & \multicolumn{2}{l}{$\begin{array}{l}\text { Personnel 's attitude } \\
\text { towards IT }\end{array}$} & Personnel use of IT \\
\cline { 2 - 5 } & $\mathrm{R}$ & $\mathrm{B}$ & $\mathrm{r}$ & $\mathrm{B}$ \\
\hline Independent variable & 0.22 & $0.24^{*}$ & 0.37 & $0.38^{\star}$ \\
\hline Perceived usefulness (PU) & 0.14 & $0.17^{*}$ & 0.36 & 0.07 \\
\hline Perceived ease of use (PEOU) & & & & \\
\hline
\end{tabular}

Model fit was measured by the evaluation of several model fit indices. The relative X2 or ratio $\mathrm{X} 2$ was used to test whether the selected distribution was a good fit to the data. A relative X2 value of 2.04 was obtained which was favorable. Tucker-Lewis index (TLI) and comparative fit indices (CFI) were measured and appeared to be acceptable. Table 4 summarizes recommended goodness-of-fit measure.

\begin{tabular}{l|l|l|l|}
\hline $\begin{array}{l}\text { Fit index } \\
\text { category }\end{array}$ & Suggested index & Suggested value & $\begin{array}{l}\text { Obtained } \\
\text { value }\end{array}$ \\
\hline Absolute fit & Relative $\mathrm{X}^{2}$ & Relative $\mathrm{X}^{2}<3.0$ & 2.04 \\
\hline Incremental fit & $\begin{array}{l}\text { Tucker-Lewis Index } \\
\text { (TLI) }\end{array}$ & $\begin{array}{l}0.90 \text { or above } \\
\text { acceptable fit }\end{array}$ & 0.91 \\
\hline Incremental fit & $\begin{array}{l}\text { Comparative fit } \\
\text { index (CFI) }\end{array}$ & 0.90 or above & 0.92 \\
\hline
\end{tabular}

Table 4 Recommended goodness-of-fit measure

Figure 2 displays the relationship between PU and PEOU on the one hand and the relationship between participants' attitude towards IT and the actual use of it on the other hand by coefficient rates. According to this figure, user attitude, which controls the actual use of IT, is influenced by perceived usefulness and perceived ease of use. This triplet (attitude, PEOU and PU) should be the main concern of policy makers and systems designers, who by offering educational programs, focusing on this triplet, could pave the ground for the acceptance of IT in healthcare organizations. 


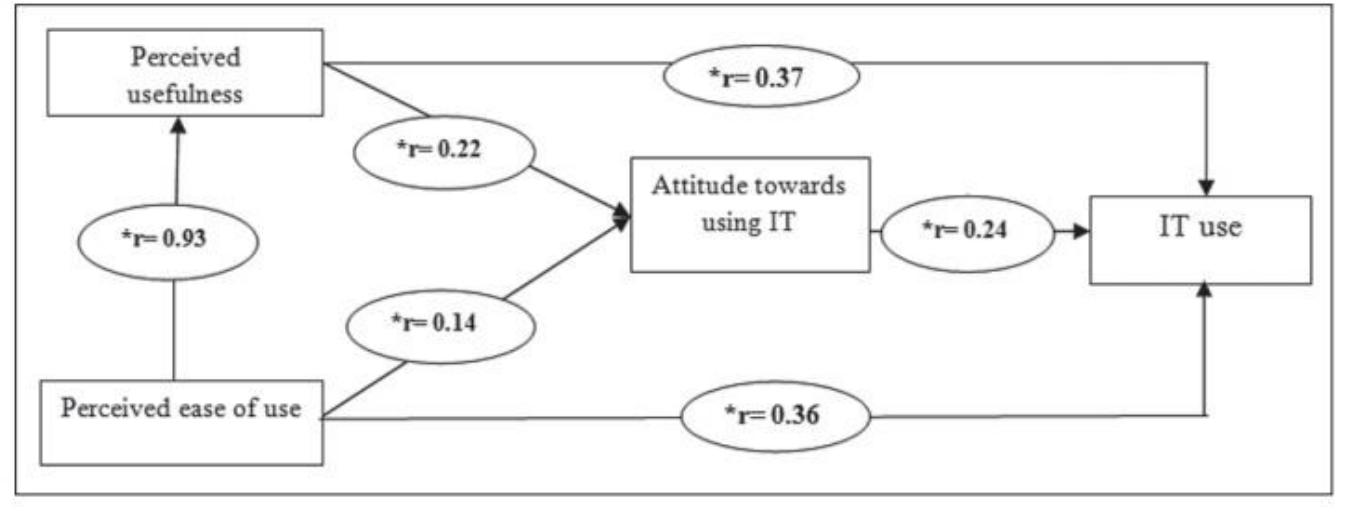

Figure 2

Assessment of the structural model (* $\mathrm{p}=0.05$ )

\section{Discussion}

Among the three barriers addressed in the introduction of this paper, human issue is the most important one in which user acceptance appears as an essential factor in determining the success or failure of information systems implementation plan [8]. With this assumption that lack of user acceptance would be a barrier to the success of IT applications [33], this study was conducted to provide evidence for the relationship between two fundamental determinants of TAM, i.e., PU and PEOU influencing the use of IT, attitude towards IT, and its use by personnel of medical records in their routine works. PU is an independent variable for predicting attitude and actual use of IT while it is a depended variable for being predicted by PEOU. The results of the present study showed that PU is positively associated with personnel's favorable attitudes towards IT ( $\mathrm{r}$ $=0.22, \mathrm{p}=0.05)$. Thus, $\mathrm{H} 1$ was supported. This finding is in line with the findings of Ortega Egea (2011) who showed that there was a significant relationship between PU and attitude $(\mathrm{r}=$ $0.39, p=0.05)$ [34]. Compared with the correlation rate of PEOU $(r=0.14, p=0.05)$, PU had a greater effect on attitude suggesting that PU had a more important role than PEOU in this study. This finding supports the findings of the study conducted by Wu et al. (2008) [35]. Pai (2010) found that there was a positive and direct relationship between PU and attitude $(\mathrm{r}=0.38, \mathrm{p}=$ 0.05) [36]. However, the findings of $\mathrm{Wu}$ et al. (2008) $(\mathrm{r}=0.49, \mathrm{p}=0.05)$ and the present study both revealed that PU had a greater effect on attitude than PEOU [35].

There are 74 studies showing a significant relationship between PU and attitude and that PU is a stronger determinant of attitude for actual use of IT [37]. These findings imply that users willingly employ IT systems when it is functionally vital [37]. The meta-analysis of a systematic review [34] on bivariate correlations between technology acceptance components revealed a strong relationship between PU and attitude, going even beyond the 'usefulness-intention' linkage. In these studies, the potential importance of PU in determining medical professionals' attitude toward the use of IT has also been acknowledged. The results of the present study showed that PU was positively associated with personnel's use of IT $(r=0.37, p=0.05)$. Zhang (2008) and Ortega Egea (2011) showed that there was a positive and direct relationship between PU and actual use ofIT $(r=0.24, p=0.05 ; \mathrm{r}=0.44, \mathrm{p}=0.05$ respectively) $[34,38]$. Overall, the 
finding that PU is positively associated with personnel's favorable attitudes towards using IT, has been addressed and acknowledged in many studies $[34,37,38)$ in which PU appears to be the main and the strongest determinant in actual use of IT and information systems. Thus, H2 was supported, suggesting that PU is positively associated with personnel's use of IT. According to the results of the present study, there was a positive direct relationship between participants' PEOU and their attitude toward IT $(r=0.14, p=0.05)$, supporting $\mathrm{H} 3$, suggesting that PEOU is positively associated with personnel's favorable attitude towards IT. These findings are in line with the findings of Wu et al. (2008), Zhang (2008) and Pai (2010) [35, 36, 38].

However, Subramanian (1994) found no significant relationship between PEOU and attitude and argued that "when systems used in studies are by their inherent nature relatively easy to use, PEOU has less or no impact on the information system acceptance decision" [27]. Similarly, Igbaria et al. (1995) remarked that "the hard reality of organizations might put priority on the usefulness of computer systems rather than the pleasure brought by them" [28]. Lee and Chao (2004) noticed that users' intention to use information systems was affected by their attitude when they found that the use of systems was less strenuous than conventional methods [26]. When examining electronic public services, Chen et al. (2008) found that a implied electronic public service system encouraged users to reuse the system [39]. In fact, these two studies inspired the researchers of the present study to scrutinize the relationship between PEOU and the actual use of IT.

The results of this study showed there was a positive direct relationship between PEOU and the actual use of IT $(\mathrm{r}=0.36, \mathrm{p}=0.05)$ which supported $\mathrm{H} 4$, indicating that PEOU is positively associated with personnel's use of IT. The findings of the present study supports the findings of Zhang (2008) who reported similar relationship $(\mathrm{r}=0.46, \mathrm{p}=0.05)$ [38]. Chau and $\mathrm{Hu}(2002)$ and Yarbrough (2007) discussed that the important role of PU in physicians' decision about technology acceptance and their actual use of IT suggest the potential and indirect effect of PEOU on PU [6, 30]. Based on a systematic review, conducted by Lee (2003), there were only 58 studies reporting a significant relationship between PEOU and dependent variables such as attitude and actual use of IT indicating that PEOU is an unstable measure in predicting dependent variables [26]. Moreover, Gefen and Straub (2000), exploring the raising controversy on the role of PEOU in TAM, and Keil et al. (1995) examining the overall effects of PEOU in TAM, obtained similar findings [40, 41].

Despite a non-significant relationship between PEOU and attitude, reported in the literature, PEOU appeared to be an important factor in accepting IT in the present study and several similar studies such as Pai (2010) $(r=0.53, p=0.05)$ and Ortega Egea (2011) $(r=0.93, p=0.05)$ [34, 36]. The finding that PEOU was the major antecedent of PU, rather than a parallel, direct determinant of acceptance was initially reported by Davis et al. (1992). As PEOU can indirectly affect the acceptance of IT through PU [29], it could be implied from the findings of this study that PEOU should not be underestimated, as it strongly affects PU which subsequently affects attitude and actual use of IT. Hence H5 is supported, showing that PEOU is positively associated with PU. Davis et al. (1989) found that there was a direct relationship between attitude and the use of IT implying that people will intend to use an IT system when they evaluate it positively [12]. The results of the present study were in line with Davis et al.'s (1989) statement on the 
relationship between attitude and actual use of IT $(\mathrm{r}=0.24, \mathrm{p}=0.05)$ supporting H6, and suggesting that attitude towards the use of IT is associated with IT usage [17].

In particular, attitude towards the use of IT was addressed by Chau and Hu (2002) as the second most important predictor of physicians' intention to use telemedicine services [30]. Thus, positive attitude should be considered as a strong factor when acceptance of IT is concerned.

However, there are some limitations which need to be addressed and acknowledged in this study. The main limitation of the study was the self-reported use of IT instead of measuring the actual use of IT. This limitation was argued by Agarwal and Karahanna (2000), "self-reported usage is known to be subject to the common method bias, which distorts and exaggerates the causal relationship between independent and dependent variables" [42].

Another limitation of this study was 'self selection biases' of the items in the questionnaire. While users' perception and their acceptance of information systems were examined in this study; they might have falsified the results. Based on the theory that user perception and intention can change over time, therefore, it is important to evaluate these quantities at several points of time [37]. However, user perception was measured only one time in this study and this could be an additional limitation. As this study was limited to personnel of medical records departments of Tehran University of Medical Sciences, a further study in which the setting is expanded to other medical departments with more clinical staff is recommended.

\section{Conclusion}

Focusing on user acceptance of IT, the present study has added to the growing literature on this important and complicated issue. This is the first study, carried out in Iran, to examine TAM in assessing the user acceptance of IT in health information management with the aim of proposing a conceptual model for applying IT in medical records departments. Application of IT, on the basis of the findings of the present study, is an unavoidable process in health organizations where user acceptance becomes a key element and should subsequently be the major concern of health organizations. User acceptance depends on the user's perception of usefulness and ease of use which are important determinants in providing an incentive for health information management professionals to adopt IT.

The present study argues that PEOU like PU has a great direct effect on attitude towards accepting and using IT. In addition, the results revealed that PU was more important than PEOU for the participants of this study. The structural model proposed for Iran, in this study, can be used, as a model for further evaluation of information technology acceptance in other countries. The findings of the present study have highlighted the association between perceived usefulness, perceived ease of use and attitude towards accepting the use of IT with some implications for information systems designers and health policy makers. On the basis of the findings of the present study, it is suggested to explore the issues addressed in this study in the area of humancomputer interaction. Future study can focus on other clinical personnel such as physicians, pharmacists, nurses, radiologists, and managers. Other factors such as security, autonomy, management involvement, prior knowledge of IT, and diffusion of innovation characteristics 
should be examined along with TAM variables for a better understanding of IT acceptance among HIM in future studies.

Acknowledgment

We would like to thank A. Parikhani and A.Farhadi, MSc students of medical records,

for their timely and accurate data collection.

This study was funded by a grant from Tehran University of Medical Sciences.

\section{References}

1. Gupta A. Exploring the acceptance and barriers to usage of information and communication technology by Irish occupational therapists. 2010.

2. Schaper LK, Pervan GP. ICT and OTs: A model of information and communication technology acceptance and utilisation by occupational therapists. International Journal of Medical Informatics 2007; 76: S212-S21.

3. Institute MR; 2002. Available from: http://www. medrecinst.com

4. Survey HIL, editor. Healthcare Information and Management Systems Society (HIMSS). The $11^{\text {th }}$ Annual HIMSS Leadership Survey Sponsored by IBM: Trends in Healthcare Information and Technology; 2000.

5. Audet AM, Doty MM, Peugh J, Shamasdin J, Zapert K, Schoenbaum S. Information technologies: when will they make it into physicians' black bags? Medscape General Medicine 2004; 6 (4).

6. Yarbrough AK, Smith TB. Technology acceptance a mong physicians. Medical Care Research and Review2007; 64 (6): 650 - 672.

7. Lin C, Lin IC, Roan J. Barriers to Physicians' Adoption of Healthcare Information Technology: An Empirical Study on Multiple Hospitals. Journal of Medical Systems 2011: 1-13.

8. Khalifa M, Liu V. The state of research on information system satisfaction. Journal of Information Technology Theory and Application (JITTA) 2004; 5 (4): 4.

9. Malcolm CL. Five e-business strategies you can take to the bank. Healthcare financial management. Journal of the Healthcare Financial Management Association 2001; 55 (9): 72.

10. Yarbrough AK, Smith TB. Technology Acceptance among Physicians - A New Take on TAM. Medical Care Research and Review 2007; 64 (6): 650 - 672. 
11. Lorenzi NM, Riley RT. Organizational aspects of health informatics: managing technological change. New York: Springer-Verlag ; 1995.

12. Davis FD, Bagozzi RP, Warshaw PR. User acceptance of computer technology: a comparison of two theoretical models. JSTOR; 1989. pp $982-1003$.

13. Venkatesh V, Morris MG, Davis GB, Davis FD. User acceptance of information technology: Toward a unified view. MIS quarterly 2003. Pp 425 - 478.

14. Rogers EM. Diffusion of innovations. Free Pr;1995.

15. Fishbein M, Ajzen I. Belief, attitude, intention, and behavior: An introduction to theory and research. Addison-Wesley Pub. Co.; 1975.

16. Venkatesh V, Davis FD. A theoretical extension of the technology acceptance model: four longi tudinal field studies. Manage Sci 2000; 46 (2): 186 -204.

17. Davis FD. Perceived usefulness, perceived ease of use, and user acceptance of information technology. JSTOR; 1989. pp $319-340$.

18. Koivunen M. Acceptance and use of information technology among nurses in psychiatric hospitals.2009.

19. Duyck P, Pynoo B, Devolder P, Voet T, Adang L, Vercruysse J. User Acceptance of a Picture Archiving and Communication System--Applying the Unified Theory of Acceptance and Use of Technology in a Radiological Setting. Methods In f Med 2008; 47 (2): 149 -156.

20. Morton ME. Use and Acceptance of an Electronic Health Record: Factors Affecting Physician Attitudes. Drexel University; 2008.

21. Holden RJ, Karsh BT. The technology acceptance model: its past and its future in health care. Journal of Biomedical Informatics 2010; 43 (1): 159 -172.

22. Hulse NC DFG, Rocha RA. Modeling end-users' acceptance of a knowledge authoring tool. Methods Inf Med 2006; 45 (5): 528 -535.

23. Gefen D, Karahanna E, Straub DW. Trust and TAM in online shopping: An integrated model. MIS quarterly 2003. pp 51-90.

24. Schepers J, Wetzels M. A meta-analysis of the technology acceptance model: Investigating subjective norm and moderation effects. Information \& Management 2007; 44 (1): 90 -103.

25. Ma Q, Liu L. The technology acceptance model: a meta-analysis of empirical findings. Journal of Organizational and End User Computing (JOEUC) 2004; 16 (1): 59 -72.

26. Lee Y, Kozar KA, Larsen KRT. The technology acceptance model: Past, present, and future. Communications of the Association for Information Systems 2003; 12 (50): 752 -780. 
27. Subramanian GH. A Replication of Perceived Usefulness and Perceived Ease of Use Measurement. Decision Sciences 1994; 25 (5-6): 863- 874.

28. Igbaria M, Iivari J. The effects of self-efficacy on computer usage. Omega 1995; 23 (6): 587605 .

29. Davis FD, Bagozzi RP, Warshaw PR. Extrinsic and Intrinsic Motivation to Use Computers in the Workplace1. Journal of Applied Social Psychology 1992; 22 (14): 1111-1132.

30. Chau PYK, Hu PJH. Investigating healthcare professionals' decisions to accept telemedicine technology: an empirical test of competing theories. Information \& Management 2002; 39 (4): 297-311.

31. Wilkins MA. Factors Influencing Acceptance of Electronic Health Records in Hospitals. Perspectives in health information management /AHIMA, American Health Information Management Association 2009; 6 (Fall).

32. Nair SV. Benefits and security of electronic health record (EHR) use by pediatric staff: A technology acceptance model (TAM)-based quantitative study: Capella University; 2012.

33. Wixom BH, Todd PA. A theoretical integration of user satisfaction and technology acceptance. Information systems research 2005; 16 (1): $85-102$.

34. Ortega Egea JM, Román González MV. Explaining physicians' acceptance of EHCR systems: An extension of TAM with trust and risk factors. Computers in Human Behavior 2011; 27 (1): 319-332.

35. Wu JH, Shen WS, Lin LM, Greenes RA, Bates DW. Testing the technology acceptance model for evaluating healthcare professionals' intention to use an adverse event reporting system. ISQHC; 2008. p 123.

36. Pai FY, Huang KI. Applying the Technology Acceptance Model to the introduction of healthcare information systems. Technological Forecasting and Social Change 2010.

37. Lee Y, Kozar KA, Larsen KRT. The technology acceptance model: Past, present, and future. 2003.p 50.

38. Zhang N, Guo X, Chen G. IDT-TAM integrated model for IT adoption. Tsinghua Science \& Technology 2008; 13 (3): $306-311$.

39. Chen YC, Shang RN, Ho TY, Hesieh SC. The behavioral intention to use e systems for employees in Public Utility Company: Analysis based on TAM and TTF. J E Bus 2008; 10 (1): $305-327$.

40. Gefen D, Straub DW. The Relative Importance of Perceived Ease of Use in IS Adoption: A Study of E-commerce Adoption. Journal of the Association for Information Systems 2000; 1. 
41. Keil M, Beranek PM, Konsynski BR. Usefulness and ease of use: field study evidence regarding task considerations. Decision Support Systems 1995; 13 (1): 75 -91.

42. Agarwal R, Karahanna E. Time flies when you're having fun: Cognitive absorption and beliefs about information technology usage. MIS quarterly 2000: 665-694. 